\title{
Effect of Carnatic Music Listening Training on Speech in Noise Performance in Adults
}

\author{
Raksha Amemane ${ }^{1}$, Archana Gundmi ${ }^{2}$, and Kishan Madikeri Mohan ${ }^{2}$ \\ ${ }^{1}$ Audiologist Banglore, Banglore, Karnataka, India \\ ${ }^{2}$ Department of Speech and Hearing, Manipal College for Health Professions, Manipal Academy of Higher Education, Manipal, \\ Karnataka, India
}

Received May 29, 2020

Revised July 16, 2020

Accepted September 8, 2020

Address for correspondence

Archana Gundmi, PhD

Department of Speech and

Hearing Manipal College

for Health Professions,

Manipal Academy of Higher Education,

Tiger Circle Road, Madhav Nagar,

Manipal, Karnataka 576104, India

Tel +9986516039

Fax +08202571915

E-mail archana.maiya@manipal.edu
Background and Objectives: Music listening has a concomitant effect on structural and functional organization of the brain. It helps in relaxation, mind training and neural strengthening. In relation to it, the present study was aimed to find the effect of Carnatic music listening training (MLT) on speech in noise performance in adults. Subjects and Methods: A total of 28 participants (40-70 years) were recruited in the study. Based on randomized control trial, they were divided into intervention and control group. Intervention group underwent a short-term MLT. Quick Speech-in-Noise in Kannada was used as an outcome measure. Results: Results were analysed using mixed method analysis of variance (ANOVA) and repeated measures ANOVA. There was a significant difference between intervention and control group post MLT. The results of the second continuum revealed no statistically significant difference between post training and follow-up scores in both the groups. Conclusions: In conclusion short-term MLT resulted in betterment of speech in noise performance. MLT can be hence used as a viable tool in formal auditory training for better prognosis.

J Audiol Otol 2021;25(1):22-26

KEY WORDS: Speech perception · Listening training · Auditory working memory.

\section{Introduction}

Music is an art of gathering and ordering the tones or sounds in a sequence. It produces a composition having both unity and continuity. Music is a ubiquitous part of everyday life for people across all age range. It has a concomitant effect on the structural and functional organization of the brain [1]. It creates psychological reaction within individuals when it passes through the auditory cortex of the brain [2].

Music and speech are two complex forms of auditory stimuli. Even though music and speech are different they share few common elements such as timbre, pitch, and timing [3]. Hence expertise in music results in enhanced speech perception. This might be because of the shared neural pathways for both music and speech [4]. Music training is thought to be a strong

This is an Open Access article distributed under the terms of the Creative Commons Attribution Non-Commercial License (https://creativecommons.org/licenses/by-nc/4.0/) which permits unrestricted non-commercial use, distribution, and reproduction in any medium, provided the original work is properly cited. driver of neural plasticity $[5,6]$. Hence musicians exhibit superior performance in terms of auditory perception [7-9], working memory [10], auditory attention $[7,8]$ and understanding speech in noise [11-13].

Recent evidence has stated that long- term musical training results in a change in the plasticity of the cortical and sub-cortical neurons, which strengthens the mechanisms involved in auditory processing [14]. However, long term music training is not a viable tool in rehabilitation. Studies have postulated that even short-term musical training results in enhanced performance in auditory and cognitive skills [15-17]. Even passive participation in short term perceptual music listening tasks has shown enhancement of speech perception in noise scores in young non-musicians [4].

The form of music also has an impact where in each form of music offers unique sets of benefits. The present study was aimed at finding the benefits of Carnatic music which is a form Indian music. Indian classical music form is mainly based on Raga and Tala which is different from western music, com- 
posed of melody and rhythm [18]. Ragas are the sequential arrangement of notes that invoke the emotion of a song and they are regarded to be much more complex than melody.

Indian classical music can be broadly classified into South Indian Carnatic music and North Indian Hindustani music. The notes in Carnatic music are arranged and rendered in a complex way when compared to Hindustani music [19]. Carnatic music differs from other forms of Indian style of music due to the presence of microtones, Gamakas and the style of representation [20]. In Carnatic music, Kalyani and Mayamalavagowla raga are the basic forms of ragas. Active or passive participation in Carnatic music has several benefits. It stimulates the brain pathways which process the spatial reasoning skills and also results in positive state of mind, helps in relaxation and enhances memory [21].

The present study used a paradigm wherein the basic forms of Carnatic music were used as a training tool for a short duration. The study focused on middle aged and older individual. Aging is one of the contributing factors leading to difficulty in understanding speech in presence of noise. Hence they become the real potential candidates. Thus, the research work was taken to study the effect of Carnatic music listening training on speech in noise performance in adults.

\section{Subjects and Methods}

A total of 28 participants ( 9 males \& 19 females) in the age range of $41-70$ years (mean age $=54.66 \pm 6.66$ ) participated in the present study. Interventional study design - a randomized control trial-was implemented. The study was approved by the Institutional Research Committee (IRC) and Institutional Ethics Committee (IEC 187/2018). CTRI registration (CTRI/2018/07/015085) was done before the recruitment of the participants. Consent forms were signed by the participants before the commencement of the study.

\section{Demographic data}

The demographic data of the participants of control group and intervention group in terms of mean age, sex and hearing status are depicted in Table 1.

\section{Selection criteria}

Individuals who were native speakers of Kannada language were recruited. Participants had normal to mild pure tone average thresholds at $0.25-8 \mathrm{kHz}$ [22]. They had normal middle ear function and no history of cognitive and/or neurootological deficits. Those individuals with previous experience of music training and who were active music listeners were excluded from the study.

\section{Audiological evaluation}

A detailed case history was taken to ensure that the client meets the eligibility criteria. The eligible candidates were made to undergo pure tone audiometry by modified HughsonWestlake procedure [23] and speech audiometry to establish hearing thresholds. The evaluation was carried out using a dually calibrated diagnostic audiometer (Madsen Astera: ANSI S3.43-1996, GN Otometrics, Natus, Denmark). Middle ear analysis was carried out using a GSI Tympstar (Grason Stadler, Eden prairie, MN, USA), with $226 \mathrm{~Hz}$ probe tone which was delivered using an airtight probe tip (JBL T450BLU, Harman International Industries, China).

\section{Study procedure}

The participants were randomly allocated into two groups (i.e., control group and intervention group) based on randomized block sampling. A total of 14 individuals were allocated in both the intervention group and the control group. The study procedure was carried out in four stages.

\section{Stage I: pre-training evaluation}

All the participants from both groups were subjected to Quick Speech-in-Noise (QUICK-SIN) test.

\section{QUICK-SIN in Kannada test}

QUICK-SIN in Kannada (QUICK-SIN-K) [24] was used in the present study to obtain the SIN scores. The QUICKSIN-K test has a total of seven lists with seven sentences each, having five keywords. The signal to noise ratio (SNR) decreased from $8 \mathrm{~dB}$ to $-10 \mathrm{~dB}$ in $3 \mathrm{~dB}$ steps from sentences 1 to 7 in each list. All seven lists were administered in the study and to avoid the familiarity within the test material, the sentences were presented in random order for pre-training,

Table 1. Demographic details of the participants

\begin{tabular}{|c|c|c|c|c|c|c|}
\hline \multirow{2}{*}{ Group } & \multicolumn{3}{|c|}{ Age } & \multicolumn{2}{|c|}{ Sex } & \multirow{2}{*}{ Hearing status } \\
\hline & $n$ & Mean & SD & Female & Male & \\
\hline IG & 14 & 53.71 & 6.23 & 10 & 4 & Normal to mild PTA thresholds \\
\hline CG & 13 & 55.61 & 7.46 & 9 & 4 & Normal to mild PTA thresholds \\
\hline
\end{tabular}

IG: intervention group, CG: control group, PTA: pure tone average, SD: standard deviation 
post-training, and follow-up assessments. The stimulus was presented via calibrated headphones at the most comfortable level of the individuals. Participants were asked to repeat back the presented target sentences. The score of one was given for each correct keyword repetition and SNR loss was calculated from the score using the formula [SNR loss $=22.5-(-$ 6.17)-total no. of correct word].

\section{Stage II: training phase}

The participants from the intervention group underwent music listening training. In the training sessions, the participants were made to listen to a few excerpts of Carnatic music. The stimuli were presented bilaterally through a laptop and high fidelity headphones (JBL T450BLU) at the individual's comfortable level. They were made to listen to the music stimuli every day for duration of 35 minutes. Music listening training was carried out for ten consecutive days under the supervision of the primary investigator in a controlled environment.

The stimuli consisted of two basic ragas of Carnatic music i.e., Kalyani and Mayamalavagowla of the vocal and violin compositions. The music stimuli were played and sung by a male singer, female singer and also a violinist, who had an experience of more than 15 years practicing Carnatic music; they had also passed the senior level music examination and practiced music for around 2-3 hours per day. The stimuli included 6 compositions of Carnatic music (Table 2).

\section{Stage III: post evaluation}

Post-training evaluation was carried out immediately following 10th session of music listening training using the QUICKSIN-K test in the intervention group. The participants in the control group were also assessed at equivalent time points.

\section{Stage IV: follow-up}

The follow-up evaluation was carried out after one-month of termination of music listening training in the intervention group, to check the sustainability of the training effect. The participants from the control group also underwent follow-up evaluation along with intervention group using QUICK-SIN$\mathrm{K}$ test.

Table 2. Music compositions used in the study

\begin{tabular}{lll}
\hline & \multicolumn{2}{c}{ Ragas } \\
\cline { 2 - 3 } & \multicolumn{1}{c}{ Kalyani } & Mayamalavagowla \\
\hline Male voice & Nidhi Chala Sukhama & Tulasi Dhalamulache \\
Female voice & Himadri Suthe & Shri Vidhya \\
Violin & Shiva Kameshwari & Tulasi Dhalamulache \\
\hline
\end{tabular}

\section{Analytic strategy}

The SNR loss was calculated and the scores were entered into Statistical Package for Social Sciences version. 15 (SPSS, ver 15, SPSS Inc., Chicago, IL, USA) for further statisticalanalysis. Test of normality was done using Shapiro-Wilk's test. Descriptive statistics were carried out to obtain the mean and standarddeviation. Mixed method analysis of variance (ANOVA) was carried out to determine any significant difference.

\section{Results}

A total of 28 participants were recruited in the study. One participant from the control group dropped-out from the study during the post-training evaluation. Therefore, the analysis was carried out for 27 participants.

Mixed method ANOVA was performed to assess the significance between the variables. The data were interpreted for the main and interaction effects. If sphericity was violated, Greenhouse-Geisser correction will be applied. Further Bonferroni corrections were applied to check for multiple comparisons.

\section{QUICK-SIN-K scores}

Descriptive statistics obtained from mean and standard deviation were used to summarize the QUICK-SIN-K scores.

Table 3 indicates that the QUICK-SIN-K scores of the intervention group have reduced post music listening training when compared to the QUICK-SIN-K scores in the control group.

The mixed measure ANOVA indicated that there was a significant main effect of group on SNR loss $[F(1,25)=6.059$, $p=0.02, \mathrm{y}=0.195]$; further the main effect of the timeline was also significant in the intervention group $[\mathrm{F}(1.24,31.048)=$ 93.27, $p=0.001, \mathrm{y}=0.789]$. The interaction effect between group and timeline showed a significant difference between the SNR loss [F $(2.24,31.048)=89.822, p=0.001, \mathrm{y}=0.782]$. Since the interaction effect between group and timeline was significant, the analysis was extended further by splitting the group and conducting repeated measures ANOVA separately for both the groups.

Repeated measures ANOVA were conducted on the intervention and control groups. The test results of the intervention group revealed a statistically significant difference between the pre and post-training scores $(p<0.001)$, whereas the results of the control group showed no significant difference between the pre and post-training scores $(p=0.695)$. On the other hand, the results of the second continuum revealed that there was no statistically significant difference between post training and follow-up scores in the intervention group ( $p=$ $1.000)$ and the control group ( $p=0.309)$. 
Table 3. Mean and SD of pre-training, post-training, and follow-up QUICK-SIN scores of the CG and IG

\begin{tabular}{cccc}
\hline Group & Pre QUICK-SIN score & Post QUICK-SIN score & Follow up QUICK-SIN sCore \\
\hline IG & $5.03(2.62)$ & $2.26(2.27)$ & $2.23(2.25)$ \\
CG & $5.42(2.69)$ & $5.34(2.37)$ & $5.46(2.34)$ \\
\hline
\end{tabular}

QUICK-SIN: Quick Speech-in-Noise, IG: intervention group, CG: control group, SD: standard deviation

To conclude, the QUICK-SIN-K scores showed a significant change after music listening training in the intervention group, whereas the control group showed no significant changes.

\section{Discussion}

\section{Speech perception in the presence of noise}

The descriptive analysis revealed that the mean scores of QUICK-SIN-K were reduced in the intervention group when compared to the control group. Further mixed measure ANOVA and repeated measure ANOVA revealed a statistically significant difference between intervention and control group. This result indicates that there is a considerable amount of improvement in SNR with music listening training. Follow-up evaluation was carried out to assess the sustainability of a training paradigm after a duration of one month. The results revealed that there was no significant difference between post training and follow-up evaluations in the intervention group. This suggests that the effect of music listening training has persisted even after the termination of the training, showing some amount of perceptual learning in older adults.

In consensus with the present study findings, Bugos, et al [15] stated that individuals who practiced piano for at least three weeks exhibited better auditory processing skills than the control group. Mammarella, et al. [25] supports that listening excerpts of Vivaldi's resulted in immediate improvement in working memory task. Literature also revealed that 14 days of music training exhibited reliable changes in central auditory processing skills [26].

Enhanced performance in SNR can be attributed to the mechanism of processing the music and speech signal. Wherein opera hypothesis states that the processing mechanism of music and speech signal are overlapping [27]. Intense musical training enhances attention of the individual. It was also proven that, music training helps in robust activation of the left inferior frontal and right auditory regions, which is related to attention and emotional control [28]. Thus, music training facilitates neural encoding of speech signal thereby resulting in the betterment of SNR.

Hence, the overall finding of the study implies that there was a significant effect of music listening training which would further facilitate an improvement in the QUICK-SIN-K scores. Studies have stated that there was an improvement by $6-8 \%$ in speech identification scores by obtaining $1 \mathrm{~dB}$ improvement in SNR [29]. In the current study, there was a $2-3 \mathrm{~dB}$ improvement in SNR, this probably results in $16-18 \%$ of improvement in speech identification scores which further enhances the performance on speech perception in noise. This can be attributed to the form of music used in the present study.

Similarly, Jain, et al. [4] conducted a study using Carnatic music as training stimuli and gave a short period of perceptual training; the results revealed that there was a good correlation between the ability to identify ragas and speech in noise performance. However, there exists a research gap with respect to the benefits of different forms of Indian music in comparison to Western music.

Overall, the findings of this study indicate that short term Carnatic music listening training can be used as a viable tool/ strategy for enhancing the ability to understand speech-in-noise.

\section{Acknowledgments \\ None}

\section{Conflicts of interest}

The authors have no financial conflicts of interest.

\section{Author Contributions}

Conceptualization: Archana Gundmi and Kishan Madikeri Mohan. Data curation: Raksha Amemane. Formal analysis: all authors. Investigation: all authors. Methodology: all authors. Supervision: all authors. Validation:all authors. Visualization: all authors. Writingoriginal draft: Archana Gundmi and Kishan Madikeri Mohan. Writing - review \& editing: Archana Gundmi and Kishan Madikeri Mohan. Approval of final manuscript: all authors.

\section{ORCID iDs}

Raksha Amemane https://orcid.org/0000-0002-2346-8349

Archana Gundmi https://orcid.org/0000-0001-8088-5731

Kishan Madikeri Mohan

https://orcid.org/0000-0003-0703-7108

\section{REFERENCES}

1) Leisman G, Melillo R, Mualem R, Machado C. The effects of music training and production on functional brain organization and cerebral asymmetry. In: Kravchuk T, Groysman A, Soddu C, Colabella E, Leisman G, editors. Art, science, and technology. Milano: Domus Argenia In press 2012.

2) Panksepp J, Bernatzky G. Emotional sounds and the brain: the neuro-affective foundations of musical appreciation. Behav Processes 2002;60:133-55.

3) Kraus N, Skoe E, Parbery-Clark A, Ashley R. Experience-induced 
malleability in neural encoding of pitch, timbre, and timing. Ann N Y Acad Sci 2009;1169:543-57.

4) Jain C, Mohamed H, Kumar AU. The effect of short-term musical training on speech perception in noise. Audiol Res 2015;5:111.

5) Kraus N, White-Schwoch T. Music training: lifelong investment to protect the brain from aging and hearing loss. Acoust Aust 2014;42: $117-23$.

6) Münte TF, Altenmüller E, Jäncke L. The musician's brain as a model of neuroplasticity. Nat Rev Neurosci 2002;3:473-8.

7) Kraus N, Chandrasekaran B. Music training for the development of auditory skills. Nat Rev Neurosci 2010;11:599-605.

8) Strait DL, Kraus N, Parbery-Clark A, Ashley R. Musical experience shapes top-down auditory mechanisms: evidence from masking and auditory attention performance. Hear Res 2010;261:22-9.

9) Musacchia G, Sams M, Skoe E, Kraus N. Musicians have enhanced subcortical auditory and audiovisual processing of speech and music. Proc Natl Acad Sci U S A 2007;104:15894-8.

10) Pallesen KJ, Brattico E, Bailey CJ, Korvenoja A, Koivisto J, Gjedde A, et al. Cognitive control in auditory working memory is enhanced in musicians. PLoS One 2010;5:e11120.

11) Parbery-Clark A, Skoe E, Lam C, Kraus N. Musician enhancement for speech-in-noise. Ear Hear 2009;30:653-61.

12) Parbery-Clark A, Strait DL, Anderson S, Hittner E, Kraus N. Musical experience and the aging auditory system: implications for cognitive abilities and hearing speech in noise. PLoS One 2011;6:e18082.

13) Coffey EBJ, Mogilever NB, Zatorre RJ. Speech-in-noise perception in musicians: a review. Hear Res 2017;352:49-69.

14) White-Schwoch T, Woodruff Carr K, Anderson S, Strait DL, Kraus N. Older adults benefit from music training early in life: biological evidence for long-term training-driven plasticity. J Neurosci 2013;33: 17667-74

15) Bugos JA, Perlstein WM, McCrae CS, Brophy TS, Bedenbaugh PH. Individualized piano instruction enhances executive functioning and working memory in older adults. Aging Ment Health 2007;11: 464-71.

16) Moreno S, Bialystok E, Barac R, Schellenberg EG, Cepeda NJ, Chau T. Short-term music training enhances verbal intelligence and execu- tive function. Psychol Sci 2011;22:1425-33.

17) Dubinsky E, Nespoli G, Russo F. Effects of short-term choir participation on auditory perception in older adults. Can Acoust 2017;45.

18) Moreno J. Multicultural music therapy: the world music connection. J Music Ther 1988;25:17-27.

19) Ministry of Information \& Broadcasting. Annual report 1992-1993. New Delhi: Ministry of Information \& Broadcasting [cited 2020 Apr 29]. Available from: https://mib.gov.in/documents/annual-reports.

20) Vyas HM, Suma S, Koolagudi SG, Guruprasad K. Identifying gamakas in Carnatic music. In: Parashar M, Rarnesh T, Zola J, Nanjangud N, Kothapalli K, Amudha J, editors. Eighth International Conference on Contemporary Computing (IC3). Danvers, MA: IEEE;2015. p.106-110.

21) Krout RE. Music listening to facilitate relaxation and promote wellness: Integrated aspects of our neurophysiological responses to music. Arts Psychother 2007;34:134-41.

22) Goodman A. Reference zero levels for pure-tone audiometer. ASHA 1965;7:1.

23) Carhart R, Jerger JF. Preferred method for clinical determination of pure-tone thresholds. J Speech Hear Disord 1959;24:330-45.

24) Avinash M, Meti R, Kumar U. Development of sentences for quick speech-in-noise (QuickSIN) test in Kannada. J Indian Speech Hear Assoc 2010;24:59-65.

25) Mammarella N, Fairfield B, Cornoldi C. Does music enhance cognitive performance in healthy older adults? The Vivaldi effect. Aging Clin Exp Res 2007;19:394-9.

26) Lappe C, Herholz SC, Trainor LJ, Pantev C. Cortical plasticity induced by short-term unimodal and multimodal musical training. $\mathrm{J}$ Neurosci 2008;28:9632-9.

27) Patel AD. Why would musical training benefit the neural encoding of speech? The OPERA Hypothesis. Front Psychol 2011;2:142.

28) Strait DL, Kraus N. Can you hear me now? Musical training shapes functional brain networks for selective auditory attention and hearing speech in noise. Front Psychol 2011;2:113.

29) McArdle RA, Wilson RH, Burks CA. Speech recognition in multitalker babble using digits, words, and sentences. J Am Acad Audiol 2005;16:726-39. 